\title{
Rational Versus Plausible Accounting Equivalences in Preference Judgments
}

\section{Citation}

Luce, R. Duncan, 1990. Rational versus plausible accounting equivalences in preference judgments. Psychological Science 1, no. 4: 225-234.

\section{Published Version}

http://dx.doi.org/10.1111/j.1467-9280.1990.tb00205.x

\section{Permanent link}

http://nrs.harvard.edu/urn-3:HUL.InstRepos:3203260

\section{Terms of Use}

This article was downloaded from Harvard University's DASH repository, and is made available under the terms and conditions applicable to Other Posted Material, as set forth at http:// nrs.harvard.edu/urn-3:HUL.InstRepos:dash.current.terms-of-use\#LAA

\section{Share Your Story}

The Harvard community has made this article openly available.

Please share how this access benefits you. Submit a story.

Accessibility 


\section{General Article}

\section{RATIONAL VERSUS \\ PLAUSIBLE ACCOUNTING EQUIVALENCES IN PREFERENCE JUDGMENTS}

by R. Duncan Luce

Subjective expected utility (SEU) embodies four distinct principles of rational behavior. Although all have been called into some question empirically, the least plausible and least studied is the property that formally equivalent gambles are treated as indifferent in preference. The paper describes some results that arise when this property is sharply weakened and to some degree replaced by alternative rational and not-so-rationalassumptions. The resulting utility representations, like SEU, are weighted averages of the utilities of consequences, but with the weights dependent on more than the underlying chance event. In rank-dependent cases, which arise from a restricted assumption about formally equivalent gambles, the weights depend on the rank position of the corresponding consequence. In rank-and sign-dependent models, they depend both on the rank position of the consequence associated to the event and on whether it is a gain or a loss. The theory giving rise to the latter involves an additional primitive, namely, joint receipt of gambles, in terms of which new rational and irrational assumptions are invoked. The result generalizes prospect theory to gambles with more than a single gain and a single loss.

Many different qualitative axiomatizations exist for preferences over uncertain alternatives (gambles) that all lead to the well-known subjective expected utility (SEU) or to expected utility (EU) representations (see, e.g., Fishburn, 1982, 1989). In one way or another each of these axiomatizations embodies four fundamentally different principles of rationality together with some further assumptions that entail a considerable richness to the domain of gambles. Moreover, these four principles are each implied by the representation.

Aside from the more-or-less extended philosophical discussions about the logical status and actual rationality of these postulates, a gradually growing literature has

R. Duncan Luce is Victor S. Thomas Professor of Psychology, Emeritus, Harvard University and UCI Distinguished Professor of Social Sciences and Director, Irvine Research Unit in Mathematical Social Science, University of California, Irvine.

Address correspondence and reprint requests to R. Duncan Luce, Irvine Research Unit in Mathematical Behavioral Science, Social Science Tower, University of California, Irvine, CA 92717. focussed upon their descriptive accuracy. One comprehensive analysis is MacCrimmon and Larsson (1979), and Hogarth and Reder (1986) compiled a number of papers on the subject. This empirical literature is not free from controversy because it is less easy than one might first anticipate to provide unambiguous empirical evidence that bears on just a single principle without explicitly or, more often, implicitly invoking some of the others. Depending upon which principles one believes to have survived these tests, one develops alternative, more descriptive theories. In some cases these theories are simply generalizations of EU or SEU in the sense that some principles are abandoned, others accepted, and nothing inherently new and restrictive is added. In other cases, however, alternative postulates are invoked which no one claims to be aspects of rationality, but rather are suggested as more-or-less plausible descriptive principles or heuristics that actual decision makers may follow despite their acknowledged "irrationality."

My goals in this expository paper are:

- To remind the reader of the four principles underlying SEU. ${ }^{1}$

- To indicate which I am convinced are descriptively inaccurate and so must be abandoned in a descriptive theory and why I think so.

- To describe a weighted utility representation in which the weights depend not only on the event underlying the consequence but also on the relation of that consequence to both the status quo and the other consequence. This representation resembles SEU in some respects but does not imply the unwanted principles. Moreover, it generalizes prospect theory (Kahneman \& Tversky, 1979), the binary rank-dependent (or dualbilinear) theory of Luce and Narens (1985), and the general rank-dependent one of Luce (1988). It is re-

${ }^{1}$ The ones for EU are closely similar, but make explicit use of the probabilities that are present. 
lated to the original rank-dependent theory of Quiggin (1982) and later versions due to Gilboa (1987), Schmeidler (1984), and Yarri (1988). Much of this research is summarized in Wakker (1989).

- To list several plausible postulates that result in that representation but with the extra, and some may feel undesirable, wrinkle that utility is additive over the joint receipt of gambles.

\section{THE FOUR PRINCIPLES OF RATIONALITY UNDERLYING SEU}

Probably the most basic principle is transitivity of preference for choices between pairs of alternatives: if $a \geq b$, that is, a is at least as preferable as $b$, and $b \geq c$, then $a$ $z c$. The standard argument given for transitivity, at least for strict preferences, is that an intransitive person can be made to serve as a money pump. For indifference, it is far less clear that people should be transitive if there is a threshold separating preferences from indifferences. Alternative postulates have been proposed (see, e.g., Fishburn, 1985), but effectively meshing intransitive indifference with the other principles has proved relatively intractable.

The second principle is a form of dominance that can be described as follows: If a consequence in a gamble is replaced by a more preferred consequence (where this more preferred consequence may itself be a gamble), then the resulting gamble is preferred to the original one. This goes under many names, such as "independence," but mostly these terms refer to it in conjunction with one or another accounting equivalence, discussed below, and so I avoid using them. My preferred term is the mathematical one, monotonicity, although dominance is good except for the fact it is readily confused with the next principle. Cancellation, another mathematical term, is sometimes used, apparently always in isolation from other principles.

The third is generally called stochastic dominance when probabilities are known. There seems to be no agreed upon term for uncertain events. Perhaps likelihood dominance is suitable. For binary gambles (ones with just two consequences), it says that if a new gamble is formed by making the more preferred consequence more likely, then the modified gamble will be preferred to the original one.

The last principle of rationality asserts indifference between formally equivalent framings of a gamble. For a general discussion of framing, see Tversky and Kahneman (1981, 1986). A major consequence of this postulate, and the one used in the theories, is that one can always reduce a compound gamble-one in extensive (or tree) form-to its one-stage, formally equivalent normal form, and the extensive form and its corresponding normal form are indifferent in preference.

For money gambles with known probabilities, the last principle means that such gambles can be treated as random variables, and economists especially have grown so accustomed to this simplifying feature that they typically postulate a family of random variables as the domain over which preferences are defined. This has been the case for several versions of the rank-dependent theories that have arisen in the 1980s; see below for some of the references. It should always be recognized that this familiar step either limits the theory to gambles in normal form-I call them first-order gambles below-or if applied to higherorder or compound gambles it implicitly invokes the fourth, and very strong, principle of rationality.

In the absence of known probabilities, the assumption of no framing effects continues to be very strong. It implies the following concept of accounting equivalences: ${ }^{2}$ two gambles are judged indifferent if they give rise to the same consequences under the same conditions, ignoring the order in which different events are realized. Several examples of such equivalences are discussed below.

As long as the domain of gambles is sufficiently rich both in consequences and in chance events, these four principles are sufficient to prove that there exists a real valued function $U$ over gambles that is order preserving and a finitely additive probability measure $P$ over events such that the $U$ value of a gamble is the expected value of the $U$ values of its primitive consequences relative to $P$. To be quite explicit for the binary case, let $a \circ_{\mathrm{E}} b$ denote the gamble in which $a$ is the consequence if the event $\mathrm{E}$ occurs and $b$ otherwise, then U satisfies:

$$
\mathrm{U}\left(a \circ_{\mathrm{E}} b\right)=P(\mathrm{E}) \mathrm{U}(a)+[1-P(\mathrm{E})] \mathrm{U}(b) .
$$

Further, each of the rationality principles is implied by such a representation. It is important to recognize that this not only means that transitivity, monotonicity, and likelihood dominance are implied by the representation, as is widely acknowledged, but also that all possible accounting equivalences are also implied. This says that any two extensive forms having the same normal form are seen to be equivalent and so indifferent.

\section{WHICH PRINCIPLES FAIL DESCRIPTIVELY}

The empirical literature concerning these principles is too complex to be summarized here in detail. Rather, I

\footnotetext{
${ }^{2}$ The term apparently was first used in Luce and Narens (1985).
} 
focus on what, over time, has come to be regarded as the major evidence against each principle.

The sharpest evidence against transitivity arises from two classes of experiments. One is the often replicated preference reversal experiment (see, e.g., Bostic, Herrnstein, \& Luce, 1990; Grether \& Plott, 1979; Hamm, 1980; Karni \& Safra, 1987; Lichtenstein \& Slovic, 1971, 1973; Lindman, 1971; Mowen \& Gentry, 1980; Pommerehne, Schneider \& Zweifel, 1982; Reilly, 1982; Slovic \& Lichtenstein, 1983; Tversky, Sattath, \& Slovic, 1988; Tversky, Slovic, \& Kahneman, 1990). Basically it has this form. Within a larger context of selecting and evaluating gambles, there are pairs of gambles embedded that have the features that the two members of each pair have the same expected value and one member of the pair, called the \$-gamble, has a small probability of a reasonably large payoff and the other, called the $P$-gamble, has a far larger probability of a considerably more modest payoff. Some one third to one half of subjects (of various types) choose the $P$-gamble when the choice is presented but nevertheless assign an appreciably larger money value to the $\$$-gamble than to the $\boldsymbol{P}$-gamble. If one assumes, as seems to have been done, that the assigned money values represent choice indifferences, then these observations violate choice transitivity. Recently, several authors, using quite different experimental procedures, have raised considerable doubt about the assumed equivalence between judged and choice indifferences, which raises doubts about the degree to which these studies actually provide any evidence against the transitivity of choices (Bostic et al., 1990; Tversky et al., 1988, 1990). If these doubts are sustained, then the assumption of transitivity need not be discarded on the basis of apparent preference reversals. But, equally important, if judged indifference cannot be explained in terms of choices, then we must develop an explicit theory for judged indifferences. Such an additional theory is essential since such judgments of money equivalents play an important role in many applied contexts including much of the work carried out by decision analysts.

Tversky (1969) carried out a systematic study of the intransitivities that can be generated when successive pairs of alternative in a chain of them differ only slightly in the probabilities; the small differences were apparently ignored in favor of payoff differences. But between the ends of the chain the probability, and associated EU, difference is far too large to ignore. This phenomenon has been replicated and further studied by Budescu and Weiss (1987), Lindman and Lyons (1978), Montgomery (1977), and Ranyard (1977). It appears to be a pervasive failure of transitivity that is due primarily to insufficient attention being paid to small differences. Researchers differ in the weight they give to these demonstrations. From a theoretical perspective, it appears to be somewhat messy to take it into account-for example, it has proved difficult to combine any kind of structure with the ordinal generalization of weak orders to semi- or interval-orders.

In sum, although some evidence questions the descriptive accuracy of transitivity, I along with many other theorists believe that it is accurate enough to assume as a first, and certainly a normatively compelling, approximation.

Turning to monotonicity, the major phenomenon usually interpreted as evidence against it is the Allais paradox, again a highly robust finding. For a detailed discussion largely from an economic perspective, see Allais and Hagen (1979). I need not describe it again, except to point out that it has been demonstrated only when the gambles are presented in normal, not extensive, form. This means that what is demonstrated to be false is the combination of monotonicity and the reduction, via an accounting equivalence, from extensive to normal form. Little experimentation has been done on monotonicity when the extensive form is retained, but what exists supports monotonicity (Keller, 1985; Kahneman \& Tversky, 1979). If that is correct, then the paradox really proves only that people do not see that formally equivalent gambles are indifferent. Although descriptive validity of monotonicity is far from certain, in my opinion there is no compelling reason at present to reject it. Furthermore, many commentators feel it is on a par with transitivity as an unambiguous principle of rational behavior.

Likelihood dominance was first made descriptively suspect by Ellsberg (1961) by means of the gedanken paradox now named after him, and nothing since then has made it look more satisfactory. Since the main role of likelihood dominance in the theory is to establish the finite additivity of the probability measure, dropping it forces one to representations in which probabilities are replaced by weights with somewhat weaker properties than those of probability. Tversky (1967) ran an empirical study under conditions quite different from the Ellsberg paradox that showed the incompatibility of SEU and additive weights.

Finally, there are the accounting equivalencesincluding the many reductions from extensive to normal form. Actually, and perhaps surprisingly, very little data exists on such equivalences. When the problem of universal accounting is clearly formulated, most psychologists are deeply suspicious as to whether such insights into the structure of gambles are very widespread. Certainly, anyone who has taught decision theory is aware that many students have grave difficulty in seeing through the structure of any beyond the simplest accounting equivalences. It is in this respect that subjects' rationality is most bounded, to use a phrase first introduced by Simon $(1955,1978)$. I believe theorists should be very circumspect in postulating accounting equiva- 
Accounting Equivalences

lences, and experimentalists need to seek out those (few, I suspect) that appear descriptively valid. Which ones are postulated makes a good deal of difference in the resulting theory.

One problematic feature of these accounting equivalences is how to interpret the order in which events are carried out. The classes of theories being discussed do not include time as a variable, but quite clearly any empirical realization of a decision tree does have a strong temporal aspect. This is a clear failing of the modeling.

A mathematically disturbing aspect of giving up on the reduction to normal form is that a full theory for binary gambles does not extend in any automatic way to gambles with three distinct consequences, and one for three consequences does not extend in any simple way to either two or four, and so on. Thus, I first describe some binary theories that generalize binary SEU, and then turn to a generalization for finite, first-order gambles that is of a slightly different character.

\section{EVENT COMMUTATIVITY AND BINARY RANK-DEPENDENT REPRESENTATIONS}

The first utility paper in which the idea of rank dependence appeared is Quiggin (1982); it provided a rankdependent generalization of expected utility theory of von Neumann and Morgenstern (1974). (Yarrai (1987) gave a somewhat different axiomatization that leads to a special case of Quiggin.) The basic idea of Quiggin's (1982) rank-dependent representation is as follows: When the events are rank ordered according to preference for the consequences that are attached to them by the gamble, then the utility of the gamble is calculated to be a weighted average of the utilities of the money consequences with the weights being constructed as follows. The weight associated to the ith event is the difference between two similar terms. The first is a fixed function of the probability of the union of that $i$ th event together with all inferior events. The second is that same function of the probability of the union of all inferior events. Such "expectations" with nonadditive weights of this type are examples of Choquet (1953-54) integrals, as seems first to have been recognized by Schmeidler (1984). These integrals are described fully in Chapter VI of Wakker (1989).

Two types of modification of this axiomatization have appeared subsequently. Schmeidler (1984) and Gilboa (1987) give rank-dependent generalizations of Savage's (1954) subjective-expected utility which decisions are defined over a fixed set of states of nature of unknown probabilities. There the weights are the difference of nonadditive measures on the two sets of events, which again are Choquet integrals. Luce and Narens (1985) and Luce (1988) explore the generalization to events, also with unknown probability, but instead of acts over a fixed set of states each gamble is conditional on some individual event such as the toss of a coin, a throw of a die, or the unknown composition of colored balls in an urn. It generalizes mixture space ideas. The work being discussed here generalizes these last two papers to theories that are both rank- and sign-dependent, and so I shall focus only on them.

It should be emphasized that, unlike SEU where all the accounting equivalences hold, the issue of how the domain of gambles is formulated is extremely important. The lack of empirical realism in the Savage-type formulation becomes acute in the rank-dependent theories.

Luce and Narens (1985) looked into the question of finding the most general interval-scale theory of binary utility on the following assumptions: indefinite iterations of binary gambles and a preference ordering that is transitive and connected (weak order), monotonic, and satisfies two of the simplest accounting equivalences, namely,

1. Idempotence: for all consequences $a$ and events $\mathrm{E}$

$$
a \circ_{\mathrm{E}} a \sim a ;
$$

2. Event Commutativity: for all consequences $a$ and $b$ and events $\mathrm{E}$ and $\mathrm{F}$,

$$
\left(a \circ_{\mathrm{E}} b\right) \circ_{\mathrm{F}} b \sim\left(a \circ_{\mathrm{F}} b\right) \circ_{\mathrm{E}} b .
$$

The first of these is a triviality. The second simply says that if $a$ is the consequence when $\mathrm{E}$ and $\mathrm{F}$ both occur and $b$ is the consequence otherwise, then it is immaterial in which order $\mathrm{E}$ and $\mathrm{F}$ are carried out. The main doubt is not subjects' ability to see through the logic, which many seem to do, but a possible preference in having one event run before the other.

Luce and Narens (1985) showed (see also Luce, 1988, for a refinement in the use of event commutativity) that together with some more technical assumptions about the richness of the domain, these assumptions imply the existence of an order preserving utility function $U$ and two weighting functions $\mathrm{S}_{>}$and $\mathrm{S}_{<}$that map events into $(0,1)$ such that for all consequences $a$ and $b$ and events $\mathrm{E}$

$$
\mathrm{U}\left(a \circ_{\mathrm{E}} b\right)=\left\{\begin{array}{l}
\mathrm{S}_{>}(\mathrm{E}) \mathrm{U}(a)+\left[1-\mathrm{S}_{>}(\mathrm{E})\right] \mathrm{U}(b), \text { if } a \geqslant b \\
\mathrm{~S}_{<}(\mathrm{E}) \mathrm{U}(a)+\left[1-\mathrm{S}_{<}(\mathrm{E})\right] \mathrm{U}(b), \text { if } a \leqslant b
\end{array}\right.
$$

This representation is said to be rank dependent, abbreviated $\mathrm{RD}$, because the weights depend upon the rank order of the consequences. In other respects it is much like SEU. It entails transitivity, monotonicity, idempotence, and event commutativity, but not the other accounting equivalences of SEU theory. 
The number of weights can be reduced from two to one by adding a further rational accounting equivalence that may well be descriptively accurate, namely,

$$
a \circ_{\mathrm{E}} b \sim b \circ_{\neg \mathrm{E}} a .
$$

where $\neg$ E means "not E." This forces the relation:

$$
S_{>}(E)+S_{<}(\neg E)=1 \text {. }
$$

A general rank-dependent theory for gambles with any finite number of distinct consequences is given in Luce (1988), but since it is a special case of the representation of Eq. (11) below I do not attempt to describe it here.

The key empirical issue about this iterated binary rank-dependent theory is the three simple accounting Eqs. (2), (3), and (5), but there is little to report yet on this. However, widespread belief and indirect evidence suggests that the representation of Eq. (4) is inadequate because it fails to reflect the very distinctive role played by the status quo in decision making. There is no place for that in a purely rank-dependent theory. So we turn to a generalization that admits a special role for the status quo.

\section{RANK- AND SIGN-DEPENDENT UTILITY}

\section{Gains, Losses, and the Status Quo}

Everyone speaks of gains and losses, and almost everyone reacts to them differently. For example, the intuitive concept of riskiness-although not the formal PrattArrow definition that is widely accepted by economistsseems to focus largely on losses (Luce \& Weber, 1986; Weber, 1988). As early as 1952 Markowitz discussed the form of the utility function on either side of no change from the status quo. Edwards (1962) pointed out that if the weights fail to add to 1 , for which he adduced empirical reasons, then necessarily the representation of utility is as a ratio scale, not an interval one. This invited speculation about the (invariant) zero of such a scale, and Edwards (1962) suggested that the status quo was a natural possibility. Probably the most extensive recent such discussion is that of Kahneman and Tversky (1979), whose prospect theory assigns to the status quo a very special role. In particular, there is a major difference in computing the utility of gambles whose consequences are both on the same side relative to the status quo from those that span it. Indeed, their theory exhibits both a rank-dependent aspect and a sign-dependent one.

My purpose is, first, to describe more fully the nature of weighted linear representations that are both rank and sign dependent, and then to describe one way to arrive at that representation using some "plausible" accounting equivalences that are based on having an operation of joint receipt of gambles. General results about concatenation structures with singular points, like maxima, minima, and no change from the status quo, are worked out in Luce (1990), and the utility results described below are in Luce (in press) and Luce and Fishburn (in press). It should be noted that when a structure has singular points, its representation is as a ratio scale rather than an interval scale. Thus, forms far more general than weighted averages are possible. They are fully characterized for the binary case, but not more generally. These have not yet been investigated within the context of preferences among gambles, but these richer possibilities should not be ignored.

\section{The RSD Representation of Preferences Between Binary Gambles}

Let $e$ denote no change from the status quo. Purely formally, one can generalize the rank-dependent representation to take into account both the relation of $a$ to $b$ and each to $e$. This yields:

$$
\begin{aligned}
& \mathrm{U}\left(a \bigcirc_{\mathrm{E}} \mathrm{b}\right)= \\
& \mathrm{U}(a) \mathrm{S}_{>}{ }^{+}(\mathrm{E})+\mathrm{U}(b)\left[1-\mathrm{S}_{>}+(\mathrm{E})\right], \text { if } a \gtrsim b \gtrsim e \\
& \mathrm{U}(a) \mathrm{S}_{<}{ }^{+}(\mathrm{E})+\mathrm{U}(b)\left[1-\mathrm{S}_{<}{ }^{+}(\mathrm{E})\right], \text { if } b \geq a \geq e \\
& \mathrm{U}(a) \mathrm{S}_{>}{ }^{+}(\mathrm{E})+\mathrm{U}(b)\left[1-\mathrm{S}_{>}{ }^{-}(\mathrm{E})\right] \text {, if } a \geq e \geq b \\
& \mathrm{U}(a) \mathrm{S}_{<}{ }^{-}(\mathrm{E})+\mathrm{U}(b)\left[1-\mathrm{S}_{<}{ }^{+}(\mathrm{E})\right] \text {, if } b \geqslant e \geqq a \\
& \mathrm{U}(a) \mathrm{S}_{>}-(\mathrm{E})+\mathrm{U}(b)\left[1-\mathrm{S}_{>}-(\mathrm{E})\right] \text {, if } e \geqslant a \geqslant b \\
& \mathrm{U}(a) \mathrm{S}_{<}{ }^{-}(\mathrm{E})+\mathrm{U}(b)\left[1-\mathrm{S}_{<}{ }^{-}(\mathrm{E})\right] \text {, if } e \geq b \geq a
\end{aligned}
$$

I refer to this as a rank- and sign-dependent utility representation, abbreviated RSD (Luce, in press).

Note that, like prospect theory, the RSD representation is unique up to multiplication by a positive constant, and so it is a ratio scale theory, not an interval scale one. This arises because of the highly special role of the consequence $e$, which is totally unlike any other consequence. By setting $a=b=e$ in the representation, it is easy to see that either the weights are independent of sign, resulting in the purely rank dependent representation, or $\mathrm{U}(e)=0$.

\section{Relation of Binary RSD Utility to Other Theories}

The four weighting functions can be collapsed into fewer by various assumptions.

If the weights are independent of sign:

$$
\mathrm{S}_{i}^{+}=\mathrm{S}_{\mathrm{i}}^{-}, i=>,<\text {. }
$$

then RSD-utility reduces to the RD representation. 
If the weights are independent of order:

$$
\mathrm{S}_{>}^{j}=\mathrm{S}_{<}^{j}, j=+,-,
$$

then RSD-utility reduces to a purely sign-dependent representation (which can be shown to lead to an implausible prediction).

If the diagonals are equated:

$$
\mathrm{S}_{>}^{+}=\mathrm{S}_{<}{ }^{-} \text {and } \mathrm{S}_{<}{ }^{+}=\mathrm{S}_{>}^{-} \text {. }
$$

then the result is a slight generalization of Kahneman and Tversky's (1979) prospect theory for binary gambles. It reduces exactly to binary prospect theory by adding the rational accounting equivalence (5). For the RSD-model, this is equivalent to:

$$
\mathrm{S}_{>}^{j}(\mathrm{E})+\mathrm{S}_{<}^{j}(<\mathrm{E})=1, j=+,-.
$$

Letting $\mathrm{S}_{>}{ }^{+}=\mathrm{S}$, the representation becomes

$$
\begin{aligned}
& \mathrm{U}\left(a \circ_{\mathrm{E}} b\right)= \\
& \mathrm{U}(a) \mathrm{S}(\mathrm{E})+\mathrm{U}(b)[1-\mathrm{S}(\mathrm{E})], \quad \text { if } a \geqslant b \geqslant e \\
& \text { or } e \geq b \geq a \\
& \mathrm{U}(a) \mathrm{S}(\mathrm{E})+\mathrm{U}(b) \mathrm{S}(\neg \mathrm{E}), \quad \text { if } a \geqslant e \geqslant b \\
& \text { or } b \geq e \geqslant a \text {, } \\
& \mathrm{U}(a)\left[1-\mathrm{S}\left({ }_{\neg} \mathrm{E}\right)\right]+\mathrm{U}(b) \mathrm{S}\left({ }_{\neg} \mathrm{E}\right), \text { if } b \geq a \geqslant e \\
& \text { or } e \geq a \geqslant b
\end{aligned}
$$

which is binary prospect theory.

\section{A RSD Representation for First-Order Gambles}

As was earlier noted, once we abandon the assumption of universal accounting equivalences, the binary theory does not automatically extend to a theory of gambles of any finite size. One needs to consider carefully the general form of the representation, explore its relation to the binary theory, and axiomatize it. In this subsection I describe one proposal (Luce \& Fishburn, in press) that is a natural generalization of prospect theory and that agrees with the general RD theory of Luce (1988) for gambles whose consequences are either all gains or all losses.

Let $\varepsilon$ denote an algebra of events ${ }^{3}$ and $C$ a set of pure consequences, such as money or consumer items, but not gambles. Within $C$, let $e$ be a special consequence which intuitively should be thought of as no change from the status quo or, more generally, from an aspiration level. It is the null consequence.

${ }^{3} \mathcal{E}$ is a collection of subevents of an event such that if, $\mathrm{E}, \mathrm{F} \in \mathcal{E}$, then $\neg \mathrm{E}, \mathrm{E} \cup \mathrm{F} \in \mathcal{E}$.
A first-order gamble is a function $\mathrm{g}$ from a finite partition $\left\{\mathrm{E}_{j}\right\}$ of $\mathrm{E} \in \mathcal{E}$ into $C$. A second-order gamble is a mapping into the set of first-order ones, including the pure consequences. Let $\mathcal{G}$ denote all the first-order gambles as well as those second-order ones characterized below by the axioms. Preference over $\mathcal{G}$ is written $\geq$.

Suppose $g$ is a first-order gamble based on the partition $\left\{\mathrm{E}_{j}\right\}$ of an event $\mathrm{E}$. Denote by $\mathrm{E}(+)$ the union of all subevents that give rise under $g$ to a gain; by $\mathrm{E}(0)$, the union of events giving rise to the null consequence $e$; and by $\mathrm{E}(-)$, the union of events giving rise to a loss.

The representation involves an order preserving utility function $\mathrm{U}$ over $\mathcal{G}$ and weighting functions $\mathrm{S}^{i}$ into $[0,1]$ over event pairs $(D, E)$ with $D \subseteq E$. Suppose that $\mathrm{g}$ is a first-order gamble defined on the partition $\left\{\mathrm{E}_{1}, \ldots, \mathrm{E}_{m-1}, \mathrm{E}_{m}, \mathrm{E}_{m+1}, \ldots, \mathrm{E}_{n}\right\}$ and $\mathrm{g}\left(\mathrm{E}_{j}\right)$ is the consequence associated to $\mathrm{E}_{j}$. Suppose the subevents have been labelled from best to worst, that is, $g\left(\mathrm{E}_{j}\right)>\mathrm{g}\left(\mathrm{E}_{j+1}\right)$, $j=1, \ldots, n-1$, and $g\left(\mathrm{E}_{m}\right)=e$. Then,

$$
\begin{aligned}
\mathrm{U}(g)= & {\left[\sum_{j=1}^{m-1} \mathrm{U}\left[g\left(\mathrm{E}_{j}\right)\right] \mathrm{W}^{+}\left(\mathrm{E}_{j}\right)\right] \mathrm{S}^{+}[\mathrm{E}(+) \mid \mathrm{E}] } \\
& +\left[\sum_{j=m+1}^{n} \mathrm{U}\left[g\left(\mathrm{E}_{j}\right)\right] \mathrm{W}^{-}\left(\mathrm{E}_{j}\right)\right] \mathrm{S}^{-}[\mathrm{E}(-) \mid \mathrm{E}] .
\end{aligned}
$$

where the weights $\mathrm{W}^{i}, i=+,-$, are explicit functions of the $S^{i}$ which I need not write here. Further, if $h$ is a second-order gamble on a partition $\left\{\mathrm{E}^{+}, \mathrm{E}^{0}, \mathrm{E}^{-}\right\}$such that $h\left(\mathrm{E}^{+}\right)=h^{+}$is a first-order gamble of pure gains, $h\left(\mathrm{E}^{0}\right)=e$, and $h\left(\mathrm{E}^{-}\right)=h^{-}$is a first-order gamble of pure losses, then

$$
\mathrm{U}(h)=\mathrm{U}\left(h^{+}\right) \mathrm{S}\left(\mathrm{E}^{+} \mid \mathrm{E}\right)+\mathrm{U}\left(h^{-}\right) \mathrm{S}^{-}\left(\mathrm{E}^{-} \mid \mathrm{E}\right) .
$$

This representation, like that of prospect theory which it generalizes, partitions any gamble involving both gains and losses into those two parts, and the weights assigned to them do not generally add to 1 . If one focuses on just gains, then the representation is a pure rank-dependent one of the type discussed in Luce (1988) in which the weights $\mathrm{W}^{+}$do add to 1 . The same is true of the losses.

As written, this representation does not imply that gambles are strictly monotonic increasing in consequences, except for the binary ones. For monotonicity to hold for all first-order gambles, it is necessary and sufficient that there exists functions $S^{i}$ over events such that

$$
\mathrm{S}^{i}(\mathrm{D} \mid \mathrm{E})=\mathrm{S}^{i}(\mathrm{D}) / \mathrm{S}^{i}(\mathrm{E}) .
$$




\section{AN AXIOMATIZATION OF RSD UTILITY}

\section{Additivity of Utility Over the Joint Receipt of Consequences}

Let $\oplus$ be a binary operation over the underlying space of alternatives, where $g \oplus h$ denotes the joint receipt of both $g$ and $h$, whether they are gambles or pure consequences. An experimental realization of $\oplus$ is the duplex gambles first employed by Slovic and Lichtenstein (1968). The axiomatic theory that I describe involves the joint axiomatization of $\oplus$ along with more usual properties of gambles. (We have yet to discover an axiomatization that avoids introducing $\oplus$ ). One feature of the resulting utility function, $\mathrm{U}$, is that in the presence of other assumptions below it is highly restricted in form, as is derived in Luce and Fishburn (in press). The simplest special case, which was studied in Luce (in press) and leads to the easiest to describe results, has $U$ additive over $\oplus$, that is,

$$
\mathrm{U}(a \oplus b)=\mathrm{U}(a)+\mathrm{U}(b)
$$

Such an assumption of additivity goes contrary to a good deal of accepted belief, but with the flexibility provided by sign- and rank-dependent weights, it may not be as troublesome as one first thinks. I give one example below having to do with the asymmetry of gains and losses.

Before going into that, however, explicit mention should be made of the basic "irrationality" embodied in the additivity assumption. Given the joint receipt of two gambles, $a$ and $b$, a rational analysis would say that they should first be convolved and then the normal form gamble should be subjected to a utility analysis. The additivity hypotheses says otherwise: each gamble is evaluated separately and one simply adds the resulting utilities. For example, many of us buy both car and house insurance. Do you convolve the risks before making your decisions about the coverage to take? I have yet to find anyone who claims to do so. Each is evaluated in isolation as a distinct risk.

A number of applications of the binary additive RSD theory are given in Luce (in press). Included are definitions of buying and selling price in terms of $\oplus$. These are shown to be different from one another and also different from choice indifference under RSD theory, although not in some of its special cases, such as prospect theory. It follows readily from these definitions why people buy both lotteries and insurance. It also follows that judged indifferences will differ from choice indifference if subjects are in fact stating either a buying or a selling price. Finally, it is shown how to use money gambles to esti- mate the four weighting functions provided one has a suitable way of establishing choice indifferences.

\section{Form of the Utility Function for Money}

In the presence of some of the other axioms given below, additive utility for money can be shown to have the following power function representation (Luce, in press): There exist positive constants $k(j)$ and $\beta(j), j=$ ,+- , such that for real $x$

$$
\mathrm{U}(x)=\left\{\begin{array}{l}
k(+) x^{\beta(+)}, \text { if } x>0 \\
-k(-)(-x)^{\beta(-)}, \text { if } x<0
\end{array}\right.
$$

For many purposes, this appears to permit adequate flexibility. In particular, it does not establish any special symmetry between gains and losses unless one makes the added assumption that for money $x \oplus y=x+y$. In that case, utility is simply proportional to money. One might first think that this assumption is automatic, but a great deal depends upon the exact interpretation given to $\oplus$. For example, if one thinks of it as successive receipt in time, then it is not so clear that first gaining $x$ and then losing it is the same as $x-x=0$. Even with this assumption, the RSD theory retains much asymmetry of gambles, as discussed in the next subsection. Using the more general form for $U$ that they derived, Luce and Fishburn (in press) arrive at a second, interesting class of utility functions for money that have the property of initially exhibiting diminishing marginal utility but, after a point, changing over to growing marginal utility.

\section{Asymmetry of Reflected Gambles With a Symmetric Utility Function}

In contrast to prospect theory, additive RSD utility does not require any special assumptions about the asymmetry of $U$ for gains and losses in order to accommodate the observed asymmetry of positive and negative gambles. Suppose $U$ of money is symmetric in the sense that:

$$
\mathrm{U}(\$-x)=-\mathrm{U}(\$ x)
$$

Consider additive RSD utility applied to $x>y>e$,

$$
\begin{gathered}
\mathrm{U}\left(x \circ_{\mathrm{E}} y\right)+\mathrm{U}\left(-x \bigcirc_{\mathrm{E}}-y\right)= \\
{[\mathrm{U}(x)-\mathrm{U}(y)]\left[\mathrm{S}_{>}{ }^{+}(\mathrm{E})-\mathrm{S}_{<}{ }^{-}(\mathrm{E})\right],}
\end{gathered}
$$

which is zero, and so

$$
-\mathrm{U}\left(x \circ_{\mathrm{E}} y\right)=\mathrm{U}\left[-\left(x \circ_{\mathrm{E}} y\right)\right]=\mathrm{U}\left(-x \bigcirc_{\mathrm{E}}-y\right),
$$


if and only if the basic property giving rise to prospect theory obtains, namely, Eq. (9).

Thus, the following three suppositions are inconsistent:

- prospect theory,

- additive utility that is symmetric for money, and

- the existence of an asymmetry between a gamble and its reflection.

But if prospect theory is not assumed, then gambling decisions may exhibit such an asymmetry without having to impose an asymmetry on the utility function itself.

\section{The Major Axioms for Additive RSD Utility of Finite First-Order Gambles}

The axioms that lead to the representation of Eqs. (11) and (12) are grouped into three distinct classes, the first of which consists of three structural ones. The first structural axiom assumes that $\langle G, \gtrsim\rangle$ is a continuum. The second says that for each gamble there is a pure consequence (e.g., a sum of money) that is indifferent to it. And the third, which defines the extent to which secondorder gambles must be involved, begins with any firstorder gamble $g$, constructs its formally equivalent, second-order, sign-partitioned one, $g_{2}$, that partitions $g$ into subgambles over $\mathrm{E}(+), \mathrm{E}(0)$, and $\mathrm{E}(-)$, and asserts that $g_{2}$ is a gamble in $G$.

As an example, suppose $\mathrm{E}$ is an event (such as the toss of a die) having a partition into six subevents $\mathrm{E}_{i}, i=$ $1, \ldots, 6$, and let $\mathrm{g}$ be the gamble:

$\begin{array}{rcccccc}\text { event: } & \mathrm{E}_{1} & \mathrm{E}_{2} & \mathrm{E}_{3} & \mathrm{E}_{4} & \mathrm{E}_{5} & \mathrm{E}_{6} \\ \text { consequence: } & \$ 10 & 1 & 0 & -5 & -25 & -100\end{array}$

Then $g_{2}$ is the following second-order gamble:

$\begin{array}{rccc} & \mathrm{E}(+)= & & \mathrm{E}(-)= \\ \text { event: } & \mathrm{E}_{1} \cup \mathrm{E}_{2} & \mathrm{E}_{3} & \mathrm{E}_{4} \cup \mathrm{E}_{5} \cup \mathrm{E}_{6} \\ \text { consequence: } & g(+) & 0 & g(-)\end{array}$

where $g(+)$ and $g(-)$ are the two (conditional) gambles:

event: $E_{1} \quad E_{2}$ and $E_{4} \quad E_{5} \quad E_{6}$
consequence: $\begin{array}{llllll}\$ 10 & 1 & & \$-5 & -25 & -100\end{array}$

The second group of axioms captures several aspects of rationality. The first assumes that binary gambles exhibit monotonicity in the consequences. As was remarked earlier, this also appears to be reasonably descriptive. We do not know if more general monotonicity is also descriptive, but we do not need that assumption to arrive at Eqs. (11) and (12).

The second rationality condition postulates three things: transitivity of preference; that $\langle\mathcal{G}, \oplus, e\rangle$ is a mathematical group ${ }^{4}$, and monotonicity between the binary operation of joint receipt, $\oplus$, and the preference ordering, $\gtrsim$. This with the continuum assumption implies the existence of an order preserving function $U$ on $\mathcal{G}$ that is additive over the operation $\oplus$, which was discussed earlier. As was noted there, Luce and Fishburn (in press) do give a somewhat less restrictive axiomatization and representation, but it is sufficiently complex that I do not go into here.

The third rationality axiom is an accounting equivalence, namely, that for any gamble $g$, its second-order, sign-partitioned equivalent form $g_{2}$ is in fact indifferent to it, that is, $g \sim g_{2}$. I am not aware of any data on this assumption, but I believe that it is fairly natural for people to reframe gambles by partitioning them according to gains and losses, as in the above example.

The last rationality assumption is a form of distribution relating gambles to the operation $\oplus$. It turns out to be the source of rank dependence in the theory. Nonetheless, as stated it seems highly rational and nonobjectionable. Define $\ominus$ in terms of $\oplus$ as follows: for $c>b, d \sim c \ominus b$ iff $c \sim \mathrm{b} \oplus \mathrm{d}$. In the presence of the assumptions made so far, one can show that $c \ominus b$ always exists. If $g$ is a first-order gamble consisting of only gains and $c$ is the smallest gain, then let $g^{\prime}$ denote the gamble generated from $\mathrm{g}$ by subtracting $c$ (using $\ominus$ ) from each consequence of $g$. The assertion is that $g$ is indifferent to $g^{\prime} \oplus c$. A similar statement holds for any first-order gamble with only losses, subtracting the smallest loss from all of the others. This assumption was discussed informally by Kahneman and Tversky (1979), and to some degree it seems a highly rational reframing. It is a special case of Pfanzagl's (1959) consistency principle.

The description "plausible" of my title refers both to the consistency principle, which while rational in some sense certainly goes beyond the traditional axioms of rationality, and the next assumption, which we have called a decomposition axiom. It involves an assertion of indifference between gambles, but unlike the superficially similar rationality assertions, the gambles involved in these indifferences are not formally equivalent. The attempt is to capture something that is heuristic and descriptive, but irrational.

The decomposition axiom says that any second-order, sign-partitioned gamble is judged indifferent to the joint receipt of two independent gambles, one of which is the subgamble of gains on $\mathrm{E}(+)$ pitted against the null consequence on $\mathrm{E}(0) \cup \mathrm{E}(-)$ and the other of which is the

${ }^{4} \oplus$ is associative, $e$ is the identity, and inverses exist. 
subgamble of losses on $\mathrm{E}(-)$ pitted against the null consequence on $\mathrm{E}(+) \cup \mathrm{E}(0)$. This assumption in effect postulates a major point of irrationality on the part of decision makers in dealing with gambles having both positive and negative consequences.

Returning to our previous example, this decomposition axiom says that the given $g$ is indifferent to the joint receipt of:

$\begin{array}{rlc} & E(+)= \\ \text { event: } & E_{1} \cup \mathrm{E}_{2} \\ \text { consequence: } & g(+) & \mathrm{E}_{3} \cup \mathrm{E}_{4} \cup \mathrm{E}_{5} \cup \mathrm{E}_{6}\end{array}$

together with

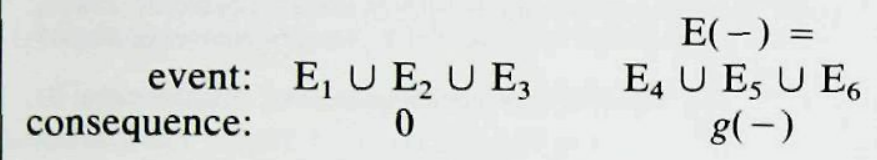

This assumption requires experimental exploration to see just how descriptive it actually is. Data in Slovic and Lichtenstein (1968) support it in the sense that most of their subjects failed to distinguish between a binary gamble with a gain and a loss and the joint receipt of the gain versus nothing and the loss versus nothing (so-called, duplex gambles).

One can show that the axioms just listed imply the representation given in Eqs. (11) and (12), and that the representation implies all but the structural ones. Specifically, it implies all of the rationality assumptions together with the last, nonrational assumption.

The theory has not yet been extended to general, higher-order or compound gambles. The difficulty in doing so resides in my uncertainty about how to cope with compound gambles whose component gambles each include both gains and losses. To be specific, suppose $g$ and $h$ are first-order gambles that each involve gains and losses, and suppose $g>e>h$. Consider the secondorder gamble $f$ on the event partition $\{\mathrm{G}, \mathrm{E}, \mathrm{H}\}$ such that $f(\mathrm{G})=g, f(\mathrm{E})=e$, and $f(\mathrm{H})=h$. It is not obvious to me whether we should generalize Eq. (12) to apply in this case, i.e.,

$$
\begin{aligned}
\mathrm{U}(f)= & \mathrm{U}(g) \mathrm{S}^{+}(\mathrm{G} \mid \mathrm{G} \cup \mathrm{E} \cup \mathrm{H}) \\
& +\mathrm{U}(h) \mathrm{S}^{-}(\mathrm{H} \mid \mathrm{G} \cup \mathrm{E} \cup \mathrm{H}),
\end{aligned}
$$

or whether $f$ should be replaced by its equivalent firstorder gamble which then is partitioned into gains and losses and Eq. (12) applied, or something else. Some data probably would be helpful in guiding the generalization.

Clearly much work needs to be done both to generalize and to investigate the adequacy of these axioms. Also, it would be desirable to arrive at an axiomatization that did not require the introduction of $\oplus$. One possible avenue might be to use conjoint methods on binary gambles with the null consequence.

Acknowledgments-Preparation of this paper was supported in part by National Science Foundation grant IRI-8996149 to the University of California, Irvine. Versions of it were presented at the conference on Utility: Theories, Measurements, and Applications, June 11-15, 1989, Santa Cruz, CA, and at the annual meeting of the Society for Mathematical Psychology, August 3-5, 1989, University of California, Irvine. I wish to thank Ward Edwards, Mark Machina, an anonymous referee, and others at the conference for helpful comments; Jerome Busemeyer for bringing several empirical studies on intransitivity of preference to my attention; and Paul Slovic for bringing to my attention the relevance of Slovic and Lichtenstein (1968) to the decomposition axiom described in the paper.

\section{REFERENCES}

Allais, M. \& Hagen, O. (eds.) (1979). Expected utility hypothesis and the Allais paradox. Dordrecht: Reidel.

Bostic, R., Herrnstein, R.J., \& Luce, R.D. (1990). The effect on the preferencereversal phenomenon of using choice indifference. Journal of Economic Behavior and Organization 13, 193-212.

Budescu, D.V., \& Weiss, W. (1987). Reflection of transitivity and intransitive preferences: A test of prospect theory. Organizational Behavior and $\mathrm{Hu}$ man Decision Processes, 39, 184-202.

Choquet, G. (1953-54). Theory of capacities. Annales de l'Institut Fourier, 5 , 131-295.

Edwards, W. (1962). Subjective probabilities inferred from decisions. Psychological Review, 69, 109-135.

Ellsberg, D. (1961). Risk, ambiguity, and the Savage axioms. Quarterly Journal of Economics, 75, 643-669.

Fishburn, P.C. (1982). The foundations of expected utility. Dordrecht: Reidel. Fishburn, P.C. (1985). Interval orders and interval graphs. New York: Wiley.

Fishburn, P.C. (1989). Retrospective on the utility theory of von Neumann and Morgenstern. Journal of Risk and Uncertainty, 2, 127-157.

Gilboa, I. (1987). Expected utility with purely subjective non-additive probabilities. Journal of Mathematical Economics, 16, 65-88.

Grether, D.M., \& Plott, C.R. (1979). Economic theory of choice and the preference reversal phenomenon. The American Economic Review, 69, 623-638.

Hamm, R.M. (1980). The conditions of occurrence of the preference reversal phenomenon. Dissertation Abstracts International, 40, 5848-5849.

Hogarth, R.M., \& Reder, M.W. (Eds.). (1986). Rational choice. Chicago: University of Chicago Press.

Kahneman, D., \& Tversky, A. (1979). Prospect theory: An analysis of decision under risk. Econometrica, 47, 263-291.

Karni, E. \& Safra, Z. (1987). "Preference reversals" and the observability of preferences by experimental methods. Econometrica, 55, 375-385.

Keller, L.R. (1985). The effects of problem representation on the sure-thing and substitution principles. Management Science, 31, 738-751.

Lichtenstein, S., \& Slovic, P. (1971). Reversals of preference between bids and choices in gambling decisions. Journal of Experimental Psychology, 89, 46-55.

Lichtenstein, S., \& Slovic, P. (1973). Response-induced reversals of preference in gambling: An extended replication in Las Vegas. Journal of Experimental Psychology, 101, 16-20.

Lindman, H.R. (1971). Inconsistent preferences among gambles. Journal of Experimental Psychology, 89, 390-397.

Lindman, H.R., \& Lyons, J. (1978). Stimulus complexity and choice inconsistency among gambles. Organizational Behavior and Human Performance. 21, 146-159.

Luce, R.D. (1988). Rank-dependent, subjective expected-utility representations. Journal of Risk and Uncertainty, 1, 305-332.

Luce, R.D. (in press). Rank- and sign-dependent linear utility models for binary Journal of Economic Theory.

Luce, R.D. (1990). Concatenation structures that are homogeneous between singular points. Manuscript in preparation.

Luce, R.D., \& Fishburn, P.C. Rank- and sign-dependent linear utility models for finite first-order gambles. Journal of Risk and Uncertainty, (in press).

Luce, R.D., \& Narens, L. (1985). Classification of concatenation structures according to scale type. Journal of Mathematical Psychology, 29, 1-72.

Luce, R.D., \& Weber, E.U. (1986). An axiomatic theory of conjoint, expected risk. Journal of Mathematical Psychology, 30, 188-205.

MacCrimmon, K.R., \& Larsson, S. (1979). Utility theory: Axioms versus 
"paradoxes". In M. Allais \& O. Hagen (Eds.), Expected utility hypothesis and the Allais' paradox (pp. 333-409). Dordrecht: Reidel.

Markowitz, H. (1952). The utility of wealth. Journal of Political Economy, 60 , 151-158.

Montgomery, H. (1977). A study of intransitive preferences using a think aloud procedure. In H. Jungerman \& G. de Zeeuw (Eds.), Decision making and changes in human affairs. Dordrecht: Ridel.

Mowen, J.C., Gentry, J.W. (1980). Investigation of the preference-reversal phenomenon in a new product introduction task. Journal of Applied Psychology, 65, 715-722.

Pfanzagl, J. (1959). A general theory of measurement-applications to utility. Naval Research Logistics Quarterly, 6, 283-294.

Pommerehne, W.W., Schneider, F., \& Zweifel, P. (1982). Economic theory of choice and the preference reversal phenomenon: A reexamination. The American Economic Review, 72, 569-574.

Quiggin, J. (1982). A theory of anticipated utility. Journal of Economic Behavior and Organization, 3, 324-343.

Ranyard, R.H. (1977). Risky decisions which violate transitivity and double cancellation. Acta Psycholgica, 41, 449-459.

Reilly, R.J. (1982). Preference reversal: Further evidence and some suggested modifications in experimental design. The American Economic Review, 72, 576-584.

Savage, L.J. (1954). The Foundations of Statistics. New York: Wiley.

Schmeidler, D. (1984). Subjective probability and expected utility without additivity: Nonaddition probabilities and convex games, Working papers at the University of Pennsylvania. Integral representation without additivity, TelAviv University, and University of Minnesota. Unpublished manuscript.
Simon, H.A. (1955). A behavioral model of rational choice. Quarterly Journal of Economics, 69, 99-118.

Simon, H.A. (1978). Rationality as process and as product of thought. The American Economic Review: Papers and Proceedings, 68, 1-16.

Slovic, P., \& Lichtenstein, S. (1968). Importance of variance preferences in gambling decisions. Journal of Experimental Psychology, 78, 646-654.

Slovic, P., \& Lichtenstein, S. (1983). Preference reversals: A broader perspective. The American Economic Review, 73, 596-605.

Tversky, A. (1967). Additivity, utility, and subjective probability. Journal of Mathematical Psychology, 4, 175-201.

Tversky, A. (1969). Intransitivity of preferences. Psychological Review, 76, 3148.

Tversky, A., \& Kahneman, D. (1981). The framing of decision and the psychology of choices. Science, 211, 453-458.

Tversky, A., \& Kahneman, D. (1986). Rational choice and the framing of decisions. Journal of Business, 59, S251-S278.

Tversky, A., Sattath, S., \& Slovic, P. (1988). Contingent weighting in judgment and choice. Psychological Review, 95, 371-384.

Tversky, A., Slovic, P., \& Kahneman, D. (1990). The causes of preference reversal. The American Economic Review, 80, 204-217.

von Neumann, J., \& Morgenstern, O. (1947). The theory of games and economic behavior. Princeton, NJ: Princeton University Press.

Wakker, P. (1989). Additive representations of preferences. Dordrecht: Kluwer. Weber, E.U. (1988). A descriptive measure of risk. Acta Psychologica, 69, 185203.

Yaari, M.E. (1987). The dual theory of choice under risk. Econometrica, 55, 95-115.

\section{American Psychological Society}

The American Psychololgical Society was founded in 1988 as an independent, multipurpose organization to advance the discipline of psychology, to preserve the scientific base of psychology, to promote public understanding of psychological science and its applications, to enhance the quality of graduate education, and to encourage the "giving away" of psychology in the public interest.

All members of the American Psychological Society receive Psychological Science and the APS Observer as part of their annual membership dues, which are $\$ 75.00$ per year through 1991. For membership information and applications contact the American Psychological Society, Suite 345, $1511 \mathrm{~K}$ Street, NW, Washington, DC 20005. Telephone: 202-783-2077; Fax 202-7832083; Bitnet: APSAGK@UMUC or APS2@UMUC.

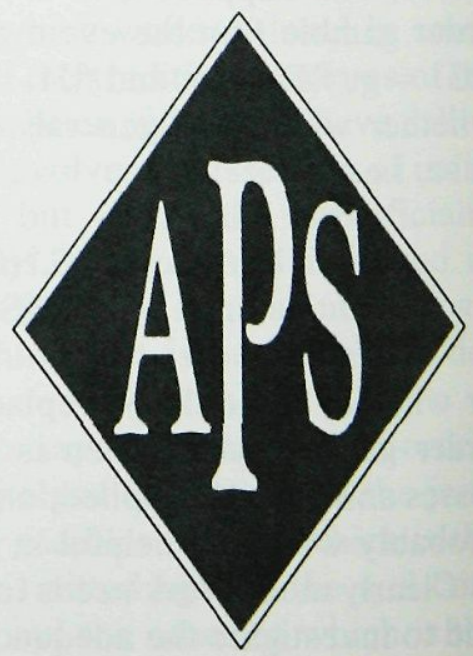


This document is a scanned copy of a printed document. No warranty is given about the accuracy of the copy. Users should refer to the original published version of the material. 